\title{
The Atmospheric radiation measurement (ARM) program network of microwave radiometers: instrumentation, data, and retrievals
}

\author{
M. P. Cadeddu ${ }^{1}$, J. C. Liljegren ${ }^{1}$, and D. D. Turner ${ }^{2}$ \\ ${ }^{1}$ Argonne National Laboratory, Argonne, IL 60439, USA \\ ${ }^{2}$ NOAA/National Severe Storms Laboratory, Norman, OK 73072, USA
}

Correspondence to: M. P. Cadeddu (mcadeddu@anl.gov)

Received: 28 February 2013 - Published in Atmos. Meas. Tech. Discuss.: 15 April 2013

Revised: 24 July 2013 - Accepted: 30 July 2013 - Published: 12 September 2013

\begin{abstract}
The Climate Research Facility of the US Department of Energy's Atmospheric Radiation Measurement (ARM) Program operates a network of ground-based microwave radiometers. Data and retrievals from these instruments have been available to the scientific community for almost $20 \mathrm{yr}$. In the past five years the network has expanded to include a total of 22 microwave radiometers deployed in various locations around the world. The new instruments cover a frequency range between 22 and $197 \mathrm{GHz}$ and are consistently and automatically calibrated. The latest addition to the network is a new generation of three-channel radiometers, currently in the early stage of deployment at all ARM sites. The network has been specifically designed to achieve increased accuracy in the retrieval of precipitable water vapor (PWV) and cloud liquid water path (LWP) with the long-term goal of providing the scientific community with reliable, calibrated radiometric data and retrievals of important geophysical quantities with well-characterized uncertainties. The radiometers provide high-quality, continuous datasets that can be utilized in a wealth of applications and scientific studies. This paper presents an overview of the microwave instrumentation, calibration procedures, data, and retrievals that are available for download from the ARM data archive.
\end{abstract}

\section{Overview of the microwave radiometers network}

For nearly two decades the ARM Climate Research Facility has been operating a network of 2-channel (23.8 and $31.4 \mathrm{GHz}$ ) ground-based MicroWave Radiometers (MWR). The radiometers have provided decadal time series of precipitable water vapor (PWV) and cloud liquid water path (LWP) at the Atmospheric Radiation Measurement (ARM) Program fixed sites: Southern Great Plains (SGP, Oklahoma, USA), North Slope of Alaska (NSA, Alaska, USA), and the Tropical Western Pacific (TWP, Darwin, Manus Island, Nauru). In addition, ARM MWRs provided year-long time series during the Surface Heat Budget of the Arctic (SHEBA) campaign (Liljegren, 2000a), and during various ARM mobile facility deployments. These data are critically important because of the key role that water vapor and liquid water path play in the earth's radiative budget (Turner et al., 2007a), in cloud-aerosol interaction (McComiskey et al., 2009) and in the climate system in general. Since their deployment, data from the MWRs have served as the reference for several ARM-sponsored water vapor studies (Revercomb et al., 2003; Mattioli et al., 2007), for comparisons of various water vapor measurement techniques involving sun photometers (Michalsky et al., 1995; Schmid et al., 2001) and the Global Positioning System (Keihm et al., 2002; Braun et al., 2003; Liou et al., 2001), as well as liquid water measurement techniques (Greenwald et al., 1999). Data from the MWRs have been widely used by the scientific community to improve gas spectroscopy in the microwave region (Liljegren et al., 2005; Payne et al., 2008; Marchand et al., 2003), to develop new retrievals of precipitable water vapor and liquid water path (Turner at al., 2007b; Turner, 2007), and for climate studies (Del Genio and Wolf, 2000; Doran et al., 2002). The MWRs also serve as the water vapor calibration reference for ARM-launched radiosondes (Turner et al., 2003; Cady-Pereira, 2008) and the operational Raman lidars at the SGP and TWP sites (Turner and Goldsmith, 1999). Consistencies in the instruments' calibration (Liljegren, 2000b) and in the data quality control (Peppler et al., 2008) have been 
key elements to ensure the repeatability and continuity of the measurements and therefore the scientific relevance of the retrievals.

Although data obtained with the 2-channel MWRs span a wide dynamic range of PWV and LWP with good sensitivity, spatial, and temporal resolution, their widespread use has revealed the need for improved measurements of PWV in very dry locations such as the Arctic (Westwater, 2001) and for improved measurements of LWP when thin liquid water clouds are present (Turner et al., 2007a). Accordingly, in recent years the ARM Program has added two MicroWave Radiometer High Frequency (MWRHF) units operating at 90 and $150 \mathrm{GHz}$, two G-band Vapor Radiometers (GVR and GVRP) operating in a frequency range between 170 and $197.3 \mathrm{GHz}$, and more recently the 3-channel radiometers (MWR3C) with frequencies at 23.834, 30, and $89 \mathrm{GHz}$. The choice of frequencies and design of the new radiometers has been driven by the scientific need to improve the accuracy in the retrieval of low amounts of integrated water vapor and cloud liquid water (Crewell and Löhnert, 2003; Racette et al., 2005; Cimini et al., 2007). The ARM infrastructure has also added two microwave temperature and humidity profilers (MWRP) with multiple frequencies between 22 and $60 \mathrm{GHz}$. Frequencies between 22 and $52 \mathrm{GHz}$ are mostly sensitive to atmospheric water in vapor and liquid phase, frequencies between 51 and $60 \mathrm{GHz}$ are sensitive to atmospheric temperature due to the absorption of atmospheric oxygen.

A view of the microwave spectrum covered by the ARM radiometers is shown in Fig. 1. It is evident that the channels near $183.3 \mathrm{GHz}$ are $10-100$ times more sensitive to water vapor than the $23.8 \mathrm{GHz}$ channel of the MWR. Similarly, frequencies near 90 and $150 \mathrm{GHz}$ are 3-5 times more sensitive to liquid water than the $31.4 \mathrm{GHz}$ channel of the MWR (Löhnert and Crewell, 2003).

All ARM microwave radiometers are co-located with several active and passive sensors such as lidars, radars, and infrared interferometers. An array of surface meteorological sensors provides continuous measurements of surface temperature, pressure, and humidity. In addition, radiosondes are regularly launched multiple times a day at each site. A summary of the radiometric network with the locations and available retrievals is shown in Table 1. Some of the radiometers can be relocated for short-term campaigns upon request. For example the GVRP was recently deployed in a research vessel in the South East Pacific during the VAMOS OceanCloud-Atmosphere-Land Study (VOCALS) (Zuidema et al., 2011) and was then deployed to Chile for the Radiative Heating in Underexplored Band Campaign II (Turner and Mlawer, 2010). Three MWRs were recently employed in a cloud-tomography experiment at the Southern Great Plains site in Oklahoma (Huang et al., 2010).

Data from all radiometers are daily reviewed by a Data Quality office (Peppler et al., 2008) that provides a first layer of data review. Additional data analysis ensures continu-

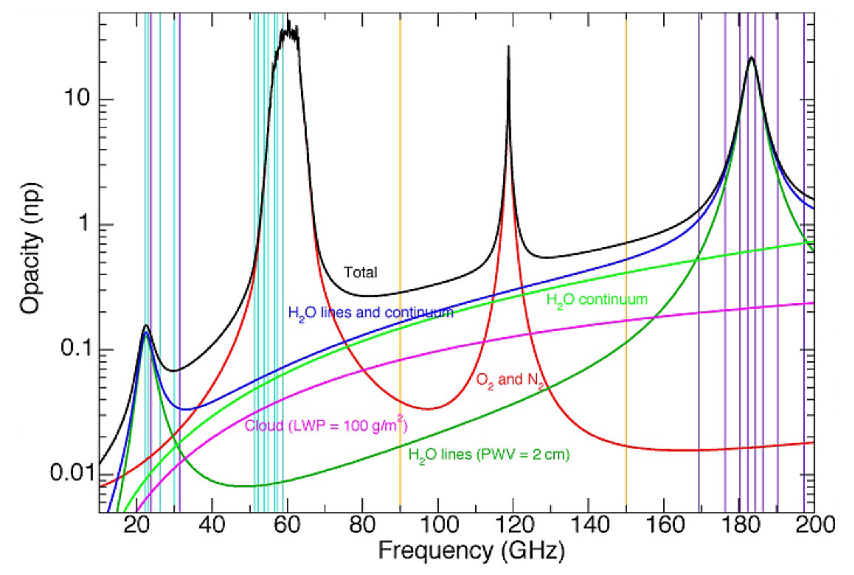

Fig. 1. The electromagnetic spectrum covered by the ARM microwave radiometers for an atmosphere with PWV of $2 \mathrm{~mm}$ and liquid water path of $100 \mathrm{~g} \mathrm{~m}^{-2}$. Vertical lines indicate the frequency location of the instruments MWR and MWRP (light blue), MWRHF (yellow), GVR and GVRP (purple).

ity in the calibration and provides reprocessing of the data as needed. Monthly reports on the instrument's status are also available from the instrument's web pages. Redundancy of instrumentation in several locations ensures meaningful comparison between independent measurements, therefore offering additional insurance on the quality of long-term instrument performance. It also provides continuity in the retrievals in case one instrument malfunctions. In the following sections, we provide an overview of the network, the calibration algorithms, data and retrievals currently available and under development.

\section{Radiometers and their calibration}

To ensure high accuracy of the retrievals, the calibration of each of the radiometers is closely monitored. Records of automated and manual calibrations are kept in a calibration database and most calibration records are also recorded in the data files. In addition, raw data files containing detector voltages and diagnostic data are stored in the data archive and are available upon request and for recalibration purposes. To eliminate the introduction of operator's judgment from the calibration process, all radiometers that employ tip curves (with the exception of the MWRP) use a self-calibration approach where acquired tip curves are continuously monitored and incorporated in the calibration algorithm with an automated process (Liljegren, 2000b). The algorithms are specifically written for the ARM radiometers and are documented in the instruments' handbooks. With the automated algorithm all radiometers are calibrated in a consistent (if not identical) fashion despite differences in manufacturers and designs. 
Table 1. Location, frequency range, date range of the ARM microwave radiometers and currently available retrievals.

\begin{tabular}{|c|c|c|c|c|c|c|}
\hline & MWR & MWRP & GVR & GVRP & MWRHF & MWR3C \\
\hline Sites & All & NSA, AMF & NSA & NSA & SGP, AMF & All \\
\hline $\begin{array}{l}\text { Center Frequencies } \\
(\mathrm{GHz})\end{array}$ & $23.8,31.4$ & $22-60$ & $183.3 \pm 1,3,7,14$ & $170-183.3$ & 90,150 & $23.8,30,90$ \\
\hline Number of channels & 2 & 12 & 4 & 15 & 2 & 3 \\
\hline Retrievals & PWV, LWP & PWV, LWP, T/H Profiles & PWV & PWV & PWV, LWP & PWV, LWP \\
\hline Algorithms & Statistical MWRRET & Statistical & $\mathrm{NN}$ & $\mathrm{NN}$ & MWRRET & NN MWRRET \\
\hline Date Range & 1993-present & 2004-present & 2006-present & 2008-present & 2008-present & 2011-present \\
\hline
\end{tabular}

\subsection{The MWR and MWRP}

The MWR, manufactured by Radiometrics Corp., is a twochannel microwave radiometer (WVR-1100 series) that operates at 23.8 and $31.4 \mathrm{GHz}$. The radiometer receiver is composed of a Gaussian optical antenna, a noise diode injection device, and two Gunn diode oscillators used for frequency selection. Each ARM fixed site and each mobile facility is equipped with one MWR (a total of 7 units). The instrument's field-of-view varies between 5 and 6 degrees depending on the frequency.

The MWRs rely entirely on tip curves for calibration. Tip curves are processed with a self-calibration algorithm that continuously monitors the gain and the receiver temperature as described in Liljegren (2000b). The algorithm applies real time corrections to account for the temperature dependence of the calibration and maintains a record of the most recent tip curves, but does not update the calibration every time a new tip curve is collected. Instead a dataset of recent successful tip curves are statistically analyzed and a median value is used to calibrate the brightness temperatures. This procedure avoids jumps in the brightness temperatures when the calibration is updated. The benefits of not updating the instantaneous tip curves are particularly evident in the highfrequency radiometers (Sect. 4). Figure 2 (top) shows one month of estimated instantaneous noise diode temperatures at the SGP. Figure 2 (bottom) shows the residual temperature dependence of the noise diode temperature (this dependence is estimated and accounted for in the calibration algorithm). During times when tip curves are not collected (mostly during prolonged times of cloudy conditions), the receiver gain is monitored through frequent viewing of the internal black body target. Noise diodes used in the radiometers are usually very stable and will work for months without drift. Therefore during times of reduced tip curves it is sufficient to calibrate the drift in the gain. If drifts in the noise diode occur data are recalibrated or flagged in Data Quality Reports (DQRs). The Root-Mean-Square (RMS) error of the calibrated brightness temperatures have been estimated to be $\sim 0.3 \mathrm{~K}$ (Liljegren, 2000b).

The Microwave Radiometer Profiler (MWRP) manufactured by Radiometrics Corp. has 12 calibrated channels of which five $(22-30 \mathrm{GHz})$ are sensitive to water vapor and

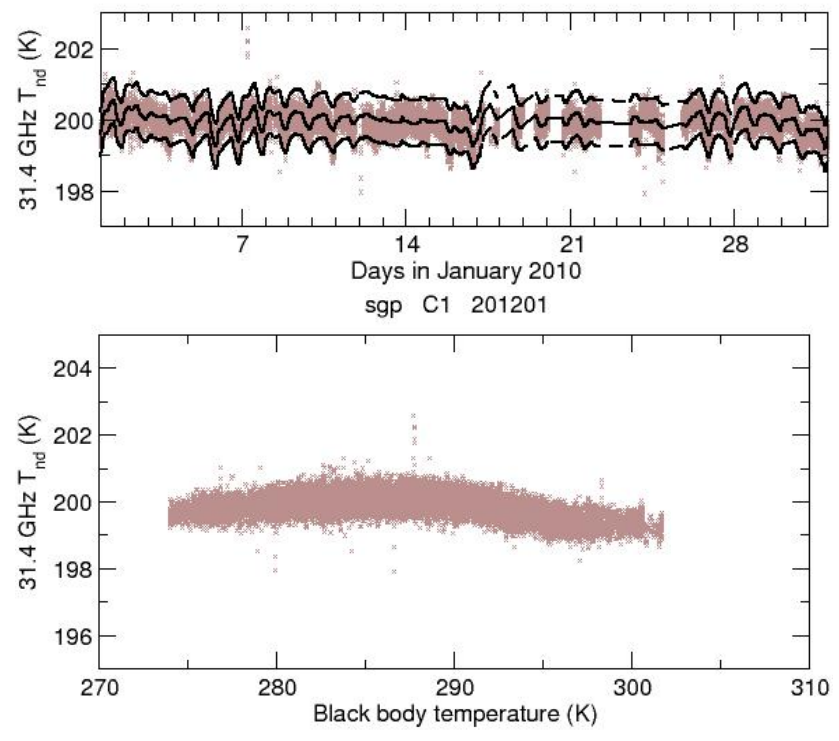

Fig. 2. Self-calibration of the ARM MWRs. Top: brown points are instantaneous noise injection temperature values derived from tip calibration. The black solid line is the median calculated value and the dashed lines are 2 standard deviations of the measurements. Bottom: dependence of the noise diode temperature on ambient temperature. The data were collected at the SGP site during the month of January 2012.

cloud liquid water and the remaining seven $(50-60 \mathrm{GHz})$ cover a frequency range that is mostly sensitive to atmospheric temperature. The frequency tuning is achieved with a frequency synthesizer that cycles through the selected frequencies serially. Frequencies between 22 and $30 \mathrm{GHz}$ are calibrated with tip curves that are monitored monthly and updated if necessary. Frequencies between 50 and $60 \mathrm{GHz}$ are calibrated with liquid nitrogen every 3-4 months. Liquid nitrogen $\left(\mathrm{LN}_{2}\right)$ calibration is a challenging aspect of the radiometers operations and the accuracy achieved by it is affected by several factors such as environment conditions and length of calibration (Solheim, 1993). $\mathrm{LN}_{2}$ calibration is less accurate where the channels are more transparent with uncertainty in the brightness temperature of approximately 1$2 \mathrm{~K}$. In addition, the $\mathrm{LN}_{2}$ calibration must be carried out with care by experienced personnel to avoid errors or injury. Two 
MWRPs are part of the network: one is located at the NSA site, and the other is part of the first ARM mobile facility (AMF1).

\subsection{GVR and GVRP}

In order to meet the demands of the scientific community for increased water vapor accuracy in dry locations, the ARM Program recently deployed two new radiometers that make measurements on the stronger $183.3 \mathrm{GHz}$ water vapor line instead of the traditional $22.2 \mathrm{GHz}$ vapor line (used by the MWRs). These G-Band Vapor Radiometers (GVR and GVRP) are now operational at the NSA site. They are specifically designed to improve the retrievals of low amounts of water vapor (less than $\sim 5 \mathrm{~mm}$ ) and are therefore particularly useful in very dry conditions such as those encountered during the Arctic winter. As shown in Section 1, the sensitivity to water vapor in the spectral region covered by these radiometers $(170-197.3 \mathrm{GHz})$ is much higher than that in the 20-30 GHz region used by the MWR.

The GVR, built by Prosensing Inc. (Pazmany, 2007; Cadeddu et al., 2007), is a filter-bank radiometer. Details of the radiometer design can be found in Pazmany (2007). The brightness temperatures are measured at four doublesideband channels centered at $\pm 1, \pm 3, \pm 7$, and $\pm 14 \mathrm{GHz}$ around the $183.31 \mathrm{GHz}$ water-vapor line. The GVR is calibrated using a warm $(\sim 293 \mathrm{~K})$ and a hot $(\sim 333 \mathrm{~K})$ FIRAM160 absorber (manufactured by the Submillimeter-Wave Technology Laboratory of the University of Massachussetts - Lowell). The absorber brightness temperatures are taken to be equal to their physical temperature. The hot absorber is enclosed in a convection-heated box. Two temperature sensors whose accuracy is $0.1 \mathrm{~K}$ (Pazmany, 2007) are located in the absorber. One sensor is near the edge and the second near the middle. Their average is used in the calibration equation as the hot load equivalent brightness temperature. This temperature uncertainty is the largest source of error in the calibration. It is accounted for in the quoted uncertainty, however it may be easily under estimated. Calibration is updated every $10 \mathrm{~s}$ which is the time necessary for the metal mirror of the radiometer to complete a cycle between the warm load, hot load and the sky. Calibration accuracy for the GVR is estimated to be about 1-2 K (Cadeddu, 2007) with higher uncertainty affecting the more transparent channels $(183.31 \pm 7$, and $\pm 14 \mathrm{GHz}$ ).

The G-Band Vapor Radiometer Profiler (GVRP) has 15 calibrated frequencies between 170 and $183.3 \mathrm{GHz}$. The radiometer, manufactured by Radiometrics Corp., is periodically calibrated with $\mathrm{LN}_{2}$. The radiometer is equipped with a noise diode that is used as a secondary calibration reference and for gain calibration. During the winter season, when the atmosphere at the site is sufficiently dry to allow tip scanning of the radiometer, the calibration of the channels between 170 and $174 \mathrm{GHz}$ is periodically double checked by processing data collected at 5 scanning angles. Calibration uncertainty for this instrument is estimated to be $\sim 1.5 \mathrm{~K}$. A comparison of measurements from the GVR and the GVRP was recently part of a broader study at the NSA and showed an overall good consistency between the radiometric measurements (Cimini et al., 2009).

\subsection{MWRHF and MWR3C}

Because of the large impact that optically thin clouds have on the earth radiative balance, the ARM Program recognized the need to provide improved retrievals of cloud-integrated liquid water by deploying microwave radiometers with channels in the 90 and $150 \mathrm{GHz}$ spectral region. These frequencies have enhanced sensitivity to the presence of optically thin clouds and they have the potential capability to reduce the root-mean-square (RMS) error of the retrievals (Löhnert and Crewell, 2003).

The Microwave Radiometer High frequency (MWRHF) (Rose et al., 2005) is built by Radiometer-Physics, GmbH, and has two channels centered at 90 and $150 \mathrm{GHz}$. The radiometer has two receiver units. A paraboloid mirror is used to focus microwave radiation that is first decomposed in two beams and then directed into a feed horn. The receivers are based on the direct detection technique, where the signal is directly amplified, filtered and detected. The radiometers calibrate with tip curves. Cryogenic calibration is only performed at the beginning of a deployment or when the instrument is powered off for extended periods of time primarily to determine the nonlinearity of the receiver's response. Raw data from this instrument are collected and calibrated with a methodology similar to that used for the MWRs and described in detail in the instrument handbook (Cadeddu, 2011) available at the instrument's website (http://www.arm.gov/ instruments/mwrhf). A schematic view of the calibration algorithm for this instrument is shown in (Cadeddu, 2011) and one month of calibration data from the $150 \mathrm{GHz}$ channel at the SGP is shown in Fig. 3. If we compare Fig. 3 with Fig. 2, we notice that the high-frequency channels have a much lower success rate in calibrating than the lower-frequency channels, and that the standard deviation of the successful tip curves is also higher. This is a consequence of the enhanced sensitivity of the high frequency channels to small perturbations in the water vapor field. In the example of Fig. 3, the resulting 1-sigma standard deviation of the calibrated brightness temperature is $\sim 1.5 \mathrm{~K}$. Tip curves are collected hourly, processed and stored. A rolling window of adjustable size is applied to the latest collected tip-curve data points and the resulting median value is then used in the calibration algorithm. Gain calibrations are conducted every few minutes by pointing the mirror towards an internal black body target. Calibration uncertainty for the MWRHF is estimated to be $\sim 1.5 \mathrm{~K}$ for the $90 \mathrm{GHz}$ channel and $\sim 2 \mathrm{~K}$ for the $150 \mathrm{GHz}$ channel.

The ARM program operates two MWRHFs: one at the SGP site and one located with the first mobile facility AMF1. A comparison of measurements from 2 MWRHF 


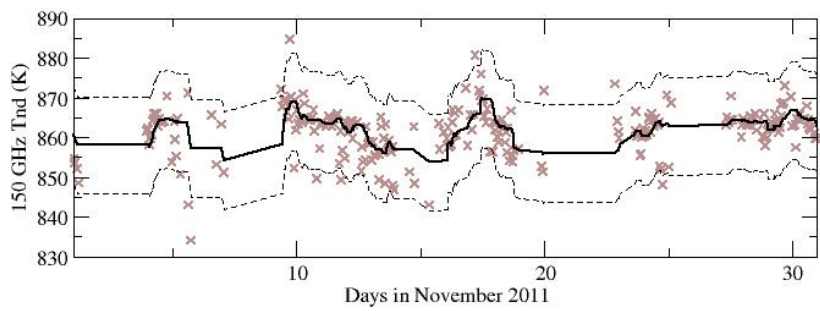

Fig. 3. Self-calibration of the ARM MWRHFs. Brown points are the instantaneous noise injection temperature values derived from tip curves. The black solid line is the median calculated value and the dashed lines are 2 standard deviations of the measurements. The data were collected at the SGP site during the month of November 2011.

radiometers during a recent deployment of the AMF1 in the Black Forest in Germany showed that the brightness temperatures of the two systems were in agreement within the calibration uncertainty (Turner at al., 2009).

A new generation of microwave radiometers (Fig. 4) is currently being deployed to replace the aging MWRs. The new radiometers (MWR3C) operate at three frequencies $23.834,30$, and $89 \mathrm{GHz}$. The instruments, manufactured by Radiometrics Corp., have been designed to ensure high temperature stability, self-calibration, narrower field-of-view ( $\sim 3$ degree for all channels), and improved operations under drizzle condition. The design of the new radiometers balances the need for continuity of operations with the desire to improve the retrievals. For this reason the new instrument retained the 2 low-frequency channels as close as possible to the old MWR (the frequency differences are due to hardware restrictions on the waveguide) at the same time introducing a narrower field-of-view that is closer to the $90 \mathrm{GHz}$ channel and to other instruments such as the infrared interferometer. They are equipped with an internal reference load that can be frequently switched on and off and whose physical temperature is measured with a precision temperature sensor. The gain is calibrated by the periodic injection of a calibrated noise generated by a noise diode. The new radiometers have been so far deployed at five ARM sites (SGP, TWP-Darwin, TWP-Manus, AMF1, AMF2) and they are in the process of being deployed at all sites. During normal operations the radiometers point to the zenith direction ( $1 \mathrm{ob}-$ servation every $\sim 10 \mathrm{~s}$ ). Zenith observations are interrupted approximately every $15 \mathrm{~min}$ to collect tip curves. The calibration algorithm for the MWR3C is designed to ensure selfcalibration and similarity of operations with the two-channel MWRs. An example of instantaneous noise diode temperatures with the calculated median value used in the calibration algorithm is shown in Fig. 5. The MWR3C can complete relatively fast azimuth rotations and can therefore be used to improve tomography studies of water vapor or cloud liquid water (Huang et al., 2010). Figure 6 (top) shows a comparison of data collected by the MWR3C and the MWR at

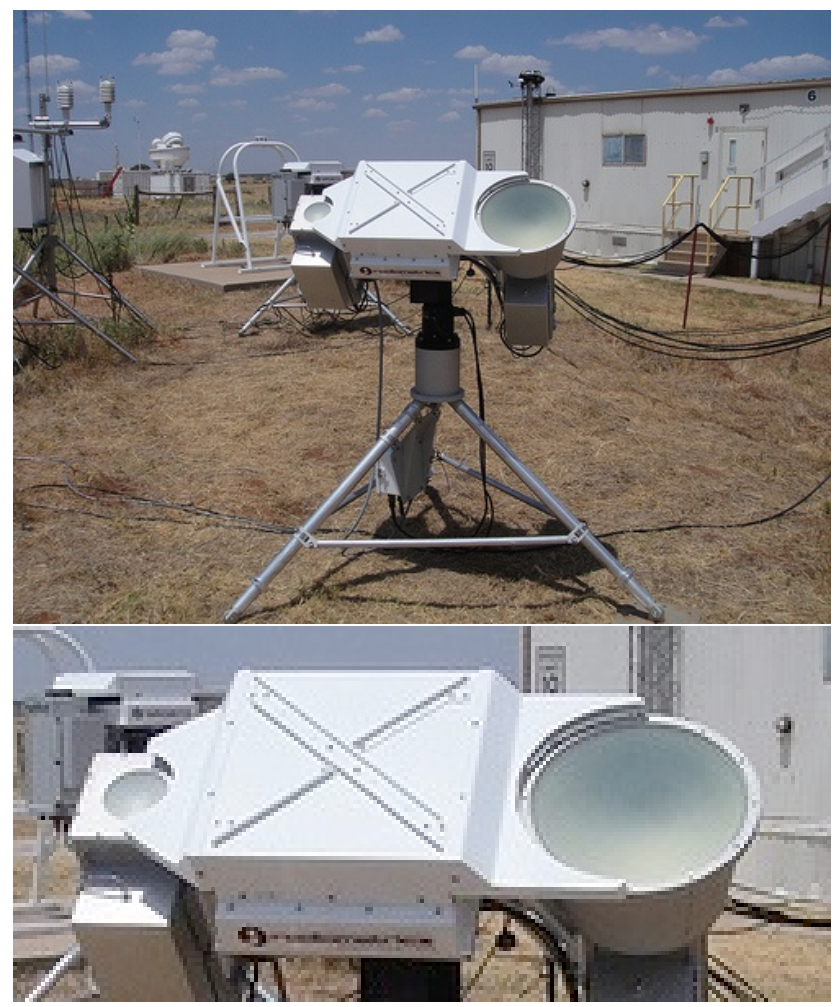

Fig. 4. The new ARM 3-channel microwave radiometer (MWR3C) with a view of the rain mitigation system.

the SGP site during the month of August 2012. The figure shows a good consistency in the measurements from the two instruments. The bottom panel of Fig. 6 shows a comparison between measurements and model computations at 89 (MWR3C) and 90 (MWRHF) GHz. Input for the model computations is provided by radiosondes soundings (4/day at the $\mathrm{SGP})$. In this and following figures, the radiometer data were averaged during the first $5 \mathrm{~min}$ of radiosonde ascent.

The rain mitigation system is designed to keep the two lenses dry in situations of high humidity, dew formation or light rain. For this purpose a stream of warm air is blown across the lenses when the relative humidity exceeds a user adjustable threshold. Air is blown at high speed during rain events to keep the lenses clear of standing water. The rain detection and mitigation system of the MWR3C shows improved capability in quickly drying the lenses after a rain event as shown in Fig. 7. The three panels show brightness temperatures $(30 \mathrm{GHz})$ during three rain events in Gan, Maldives, in December 2011. Grey crosses indicate the times when the MWR rain flag was on (100) and off (0). During these times the heater in the MWR blower was blowing warm air on the radiometer's Teflon window. The two black lines with arrows mark when the rain ends (according to the MWR3C sensor). In general the MWR rain flag stays on after the MWR3C rain rate goes to zero. This is probably due to the fact that the MWR3C sensor is sensitive to falling 


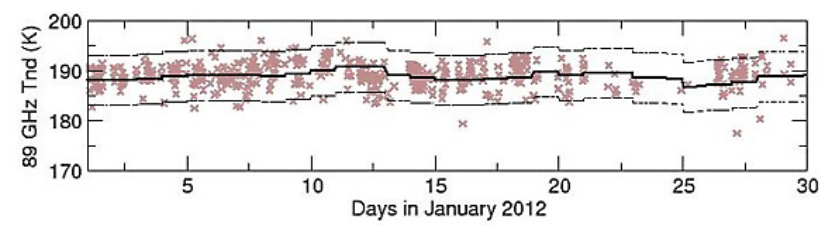

Fig. 5. Self-calibration of the ARM MWR3Cs. Brown points are the instantaneous noise injection temperature values derived from tip curves. The black solid line is the median calculated value and the dashed lines are 2 standard deviations of the measurements. The data collected at the TWP-Darwin site in January 2012.

drops while the MWR detects moisture on the sensor itself. Therefore, the MWR rain flag will stay on until the sensor is dry, although it may not be raining. We looked at the mean and standard deviation of $1 \mathrm{~h}$ of data immediately before the rain event. The brightness temperatures are considered back to normal when they are within 1 standard deviation of the computed mean (before the rain). In general the MWR3C brightness temperatures drop back to normal levels after approximately 3-9 $\mathrm{min}$ from the end of the rain, suggesting that this is the time necessary to completely free the lens of standing water. On the other hand, the MWR measurements show a slow exponential decay that can last from $10 \mathrm{~min}$ to a few hours. The slower action of the MWR blower is due to the radiometer mailbox design, where the warm air sweeps a larger curved surface, as compared to the MWR3C design where the blower outlet is mounted tightly around the round, flat lens. Figure 8 shows scatter plots of brightness temperatures at the combined AMF2-Gan, TWP-Darwin, and SGP sites at various times after a rain event. In the first $30 \mathrm{~min}$ MWR brightness temperatures are generally much higher than MWR3C's temperatures indicating rain contamination. We estimated the mean and standard deviation of the brightness temperatures in Fig. 8f (where the rain contamination is negligible) and used them as a threshold to discriminate rain contamination in the remaining cases. Based on this criterion approximately $80 \%$ of the MWR brightness temperatures normalize after the first hour (i.e. they are within 2 standard deviation of the uncontaminated mean). In a small percentage of cases (about 10\%) the rain effect on MWR brightness temperatures lasts more than $2 \mathrm{~h}$, generally in high humidity conditions.

\section{Retrievals}

Continuous retrievals of integrated water vapor and liquid water path at all sites are freely available from the ARM data archive (www.archive.arm.gov). Retrievals of vertical profiles of temperature and humidity are available at the sites where profiling radiometers are located. All retrievals use the $22 \mathrm{GHz}$ line width suggested in Liljegren at al. (2005) and the $183 \mathrm{GHz}$ line width suggested by Payne et al. (2008). The
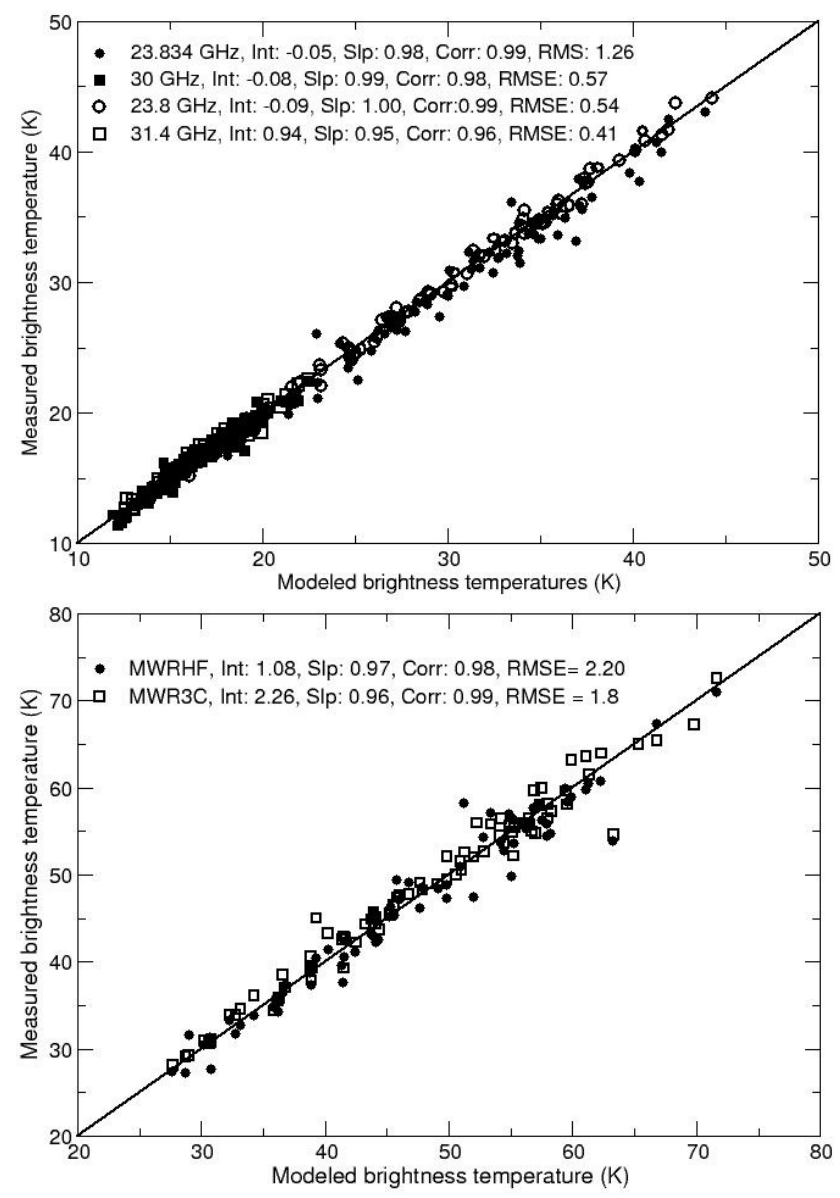

Fig. 6. Top: brightness temperatures measured and modeled at 23.834 and $30 \mathrm{GHz}$ (MWR3C, $N=81$ ) and at 23.8 and $31 \mathrm{GHz}$ (MWR, $N=84$ ). Bottom: measured and modeled brightness temperatures at $90 \mathrm{GHz}$ (MWRHF, $N=73$ ) and at $89 \mathrm{GHz}$ (MWR3C, $N=82$ ). Data were collected at the SGP site during August and October 2012.

water vapor continuum is an updated version of the CloughKneyzes-Davies 2.4 continuum (Clough et al., 1989; Mlawer et al., 2012). In the updated continuum the foreign- and selfbroadened components were scaled to improve the agreement with the high-frequency measurements (Turner et al., 2009; Payne et al., 2011). The impact of the updated continuum on the low frequency channels is negligible, however the impact of the modifications at higher frequencies (i.e. $>90 \mathrm{GHz}$ ) is larger. In this section we give an overview of the retrieval products, methodologies and expected uncertainties.

\subsection{Integrated water vapor and integrated cloud liquid water}

The primary data products derived from the ARM radiometers are PWV and LWP; these geophysical variables are among the most requested variables from the ARM data 


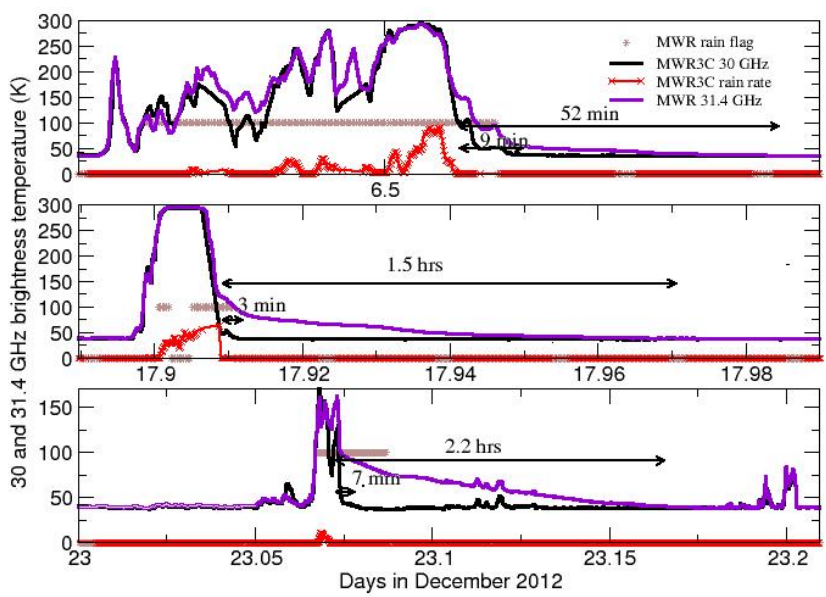

Fig. 7. Three rain events in Gan, Maldives and the effect of the response of the rain mitigation system on the MWR (violet line, 31.4 GHz) and the MWR3C (black line, $30 \mathrm{GHz}$ ). Red crosses are the rain rate $\left(\mathrm{mm} \mathrm{h}^{-1}\right)$ measured by the MWR3C weather station; brown points represent the times when the MWR rain flag was on. The black solid lines indicate the time between the end of the rain (zero rain rate according to the MWR3C) and the return of brightness temperatures to approximate pre-rain values.

archive. The improvement of these retrievals has been a major focus of the program driving the expansion of the network with the development and deployment of new microwave radiometers at all sites and especially in regions where the MWRs alone do not have enough sensitivity. New retrievals utilize channels at 23.834, 30 and $89 \mathrm{GHz}$ (MWR3C and MWRHF). In Alaska, they utilize additional channels in the $170-183 \mathrm{GHz}$ frequency range (GVR, GVRP).

There are two general retrieval methods used to retrieve water vapor and liquid water from the observed brightness temperatures: statistical methods (e.g. linear regressions, neural networks) and physical retrievals. The former use a radiative transfer model to derive a set of retrieval coefficients, typically from a climatological dataset of thermodynamic profiles from near the deployment site, whereas the latter use the radiative transfer model in an iterative fashion to modify an assumed PWV and LWP until the computed brightness temperatures match the observations within the observational uncertainty. The computational expense of the physical retrieval is several orders of magnitude larger than the statistical retrieval, but if the physical retrieval converges then the results will at least be consistent with the observations and uncertainties associated with that particular observation are produced.

ARM has used both statistical and physical retrievals to derive PWV and LWP from its original 2-channel (23.8 and $31.4 \mathrm{GHz}$ ) radiometers and the same approach is maintained with the extended network. Statistical retrievals (regression or neural network) are available real-time from the archive and are useful in situations when users want to have an im-
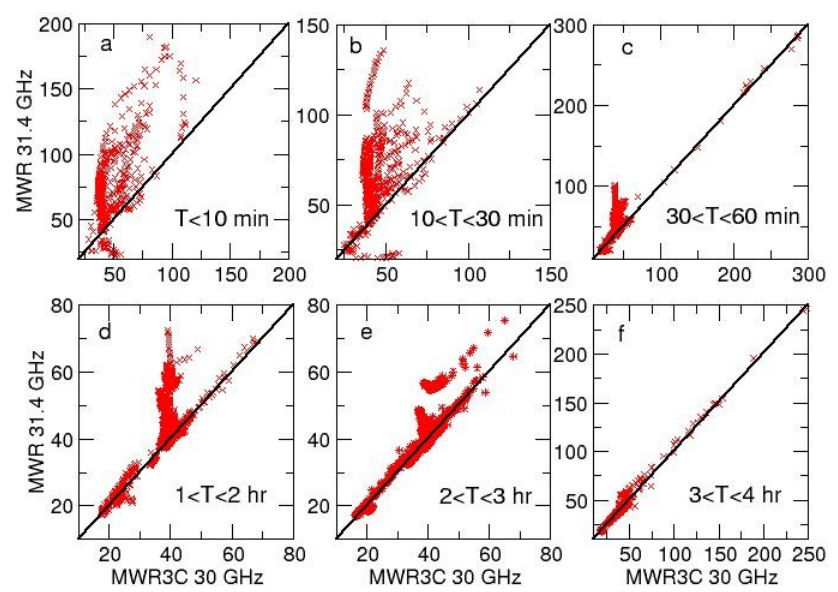

Fig. 8. Brightness temperatures collected at six time intervals from the end of rain events. Data are collected at the SGP, GAN, and TWP sites during the months of November and December 2011.

mediate estimate of the atmospheric conditions. They also provide a useful real-time check on the instrument status. Physical retrievals are available as Value Added Product in addition to the real-time retrievals. Due to the fact that they use data from multiple instruments the physical retrievals are available after 2 to 4 days after the data is collected. Below a brief description of both methodologies is provided.

\subsection{Real-time statistical retrievals}

Monthly linear regression coefficients for the 2-channel MWRs are derived by computing a simulated dataset of brightness temperatures, PWV, and LWP from a statistical ensemble of radiosondes soundings and using a linear regression algorithm to relate the simulated opacities to water vapor and cloud liquid water. The retrievals require the computation of seasonal mean radiating temperature at each site. Resulting retrieval coefficients and mean radiating temperature are then applied to the real data. Retrieval uncertainty is estimated to be $0.5 \mathrm{~mm}$ for the PWV and approximately $30 \mathrm{~g} \mathrm{~m}^{-2}$ for the LWP (Liljegren et al., 2001). Realtime neural-network (NN) retrievals (Cadeddu et al., 2009) are also available from the MWR3C, GVR, and GVRP. The neural network is trained with modeled brightness temperatures obtained from a statistical ensemble of radiosondes. Uncertainties at each retrieval point are computed by adding contributions from the training ensemble and instrumental noise. With the introduction of higher frequencies the PWV uncertainty is reduced from $0.5 \mathrm{~mm}$ to $\sim 0.3 \mathrm{~mm}$ and LWP uncertainty is reduced from $30 \mathrm{~g} \mathrm{~m}^{-2}$ to $\sim 10-15 \mathrm{~g} \mathrm{~m}^{-2}$ (depending on the frequencies used and on the location).

\subsection{Physical retrievals}

The MicroWave Radiometer Retrieval (MWRRET) is a physical retrieval described in Turner at al. (2007b). The 
method uses collocated data from active remote sensors (e.g. cloud radar, laser ceilometer) to specify the cloud altitude, and hence the cloud temperature, which significantly improves the accuracy of the retrieved LWP since the dielectric properties of liquid water emission is dependent on the ambient temperature (e.g. Cadeddu and Turner, 2011). The MWRRET method autonomously derives and applies offsets to the MWR's $31 \mathrm{GHz}$ channel to eliminate biases that could affect the retrieved LWP. The offset is most easily observed in clear sky scenes (when the LWP should be zero) and could lead to a LWP bias as large as $30 \mathrm{~g} \mathrm{~m}^{-2}$ (Turner et al., 2007b; Marchand et al., 2003).

The procurement of the new 3-channel $(23.8,31.4$, and $89 \mathrm{GHz}$ ) radiometers, as well as the desire to be able to perform physical retrievals from different combinations of radiometers (e.g. MWR and MWRHF, or MWR and GVR), led to an update of the MWRRET algorithm (version 2). Furthermore, the updated MWRRET version uses a more recent version of the radiative transfer code MonoRTM with the modifications to the gaseous absorption line and water vapor continuum described in Payne et al. (2008), Turner at al. (2009), and Payne et al. (2011). The liquid water absorption model used is described in Liebe at al. (1991).

The basic retrieval framework in the updated (version 2) MWRRET algorithm is the same as in version 1: the PWV and LWP are retrieved using an optimal estimation framework where the prior covariance matrix has very large uncertainties in the LWP and PWV as to not be a constraint in the retrieval. Profiles of temperature and humidity, which are derived from radiosonde profiles that have been interpolated to the radiometer sample time, are used to specify the vertical structure of the atmospheric state. Cloud radar and/or ceilometer data are still used to determine the height of the cloud base for the algorithm. If the active remote sensors determine that the sky is cloud free or that the cloud is in levels [above the] colder than $-40^{\circ} \mathrm{C}$ [level], then the cloud (of some yet-to-be-determined LWP) is assumed to exist at the level of maximum $\mathrm{RH}$ [below the] warmer than $-40^{\circ} \mathrm{C}$ [level]; this is done to prevent the retrieval from placing a liquid water cloud at levels where liquid water is assumed to not exist. If a cloud truly does not exist, it is hoped that the retrieved LWP will be zero within the uncertainty of the retrieval.

\subsection{Retrievals overview}

Figure 9 (top) shows the monthly PWV mean and standard deviation derived with the statistical retrieval from $12 \mathrm{yr}$ of MWR's SGP data (2000-2012, black); $10 \mathrm{yr}$ of TWPDarwin data (2002-2011, red); 12 yr of NSA data (20002012, green); and one year of AMF1 data in Graciosa Island, Azores (2010, blue). The figure illustrates the large range of PWV covered by the network $(\sim 2-60 \mathrm{~mm})$ as well as the range of seasonal variations at the sites. Figure 9 (bottom) shows median values of LWP at the four sites (negative LWP
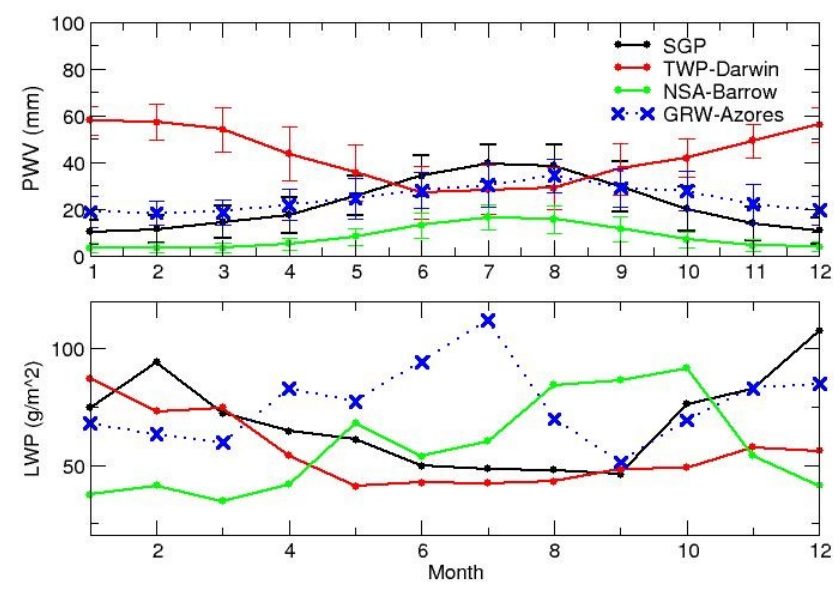

Fig. 9. Top: monthly PWV mean and standard deviation at the SGP (12 yr, black), TWP (10 yr, red), NSA (12 yr, green), and AMF1Azores (1 yr, blue). Bottom: LWP monthly median values at the same locations (only data with LWP $>0$ were included in the computation).

values were excluded from the computation of the median to avoid introducing unrealistic results). Seasonal LWP distributions at the three fixed sites (SGP, TWP-Darwin, NSA) and at the AMF1-Azores are shown in Fig. 10 together with the median and the 75th percentile of the distributions. From this figure it can be seen that the network covers a broad range of climates from the Arctic winter where clouds with low liquid water path are prevalent to spring/summer in the Azores where there is a prevalence of thicker clouds.

Focusing now on the retrievals from different radiometers, Fig. 11a shows PWV from the neural network (MWR3CNN) and MWRRET compared to the 2-channel statistical retrieval (MWR-STAT) and unscaled radiosondes data. In Fig. $11 \mathrm{~b}$ are PWV retrievals at the NSA from the MWR, the GVR and the GVRP compared to radiosonde. The retrievals display a good agreement in a water vapor range of 1 to $60 \mathrm{~mm}$ (the retrieved data are often contaminated by rain when the PWV is above $60 \mathrm{~mm}$ ). Figure 12 shows a comparison of LWP retrievals from the MWR and the MWR3C at the SGP during August 2012. The figure shows that the new 3 -channel radiometers and associated new retrievals are providing data in good agreement with the existing 2-channel MWRs.

\subsection{Discussion of retrieval uncertainty}

An important aspect of the retrieval algorithm is the estimation of the associated uncertainty. The uncertainty is estimated with various techniques depending on the retrieval methodology. Sources of uncertainty include the forward model (gas spectroscopy and liquid water dielectric properties), the radiosonde ensemble used to train the algorithm, cloud temperature, mean radiating temperature, instrument calibration and random noise. Uncertainties in the 

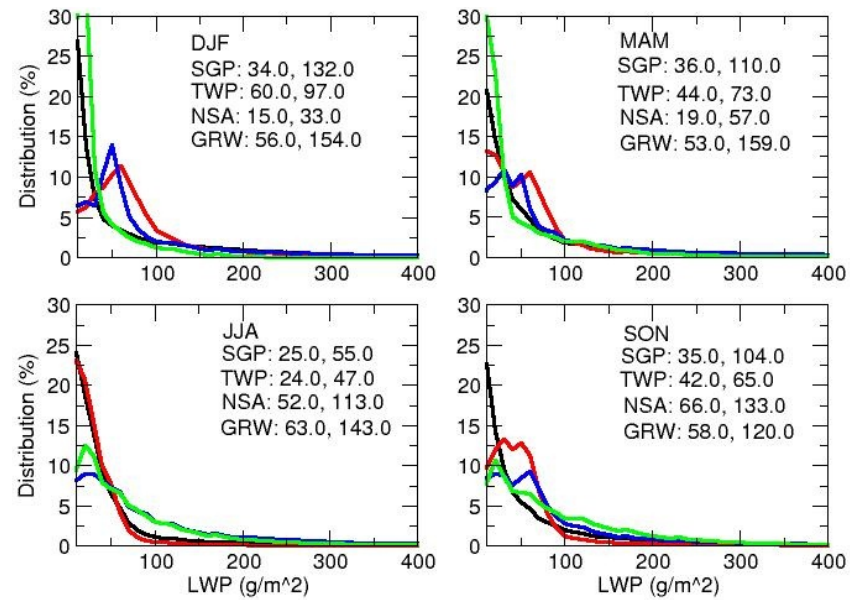

Fig. 10. Seasonal LWP distribution at the 3 fixed sites SGP (black), TWP-C3 (red), NSA (green) and at the AMF1-Azores (blue). The median and 75 percentile of the distributions are also given.
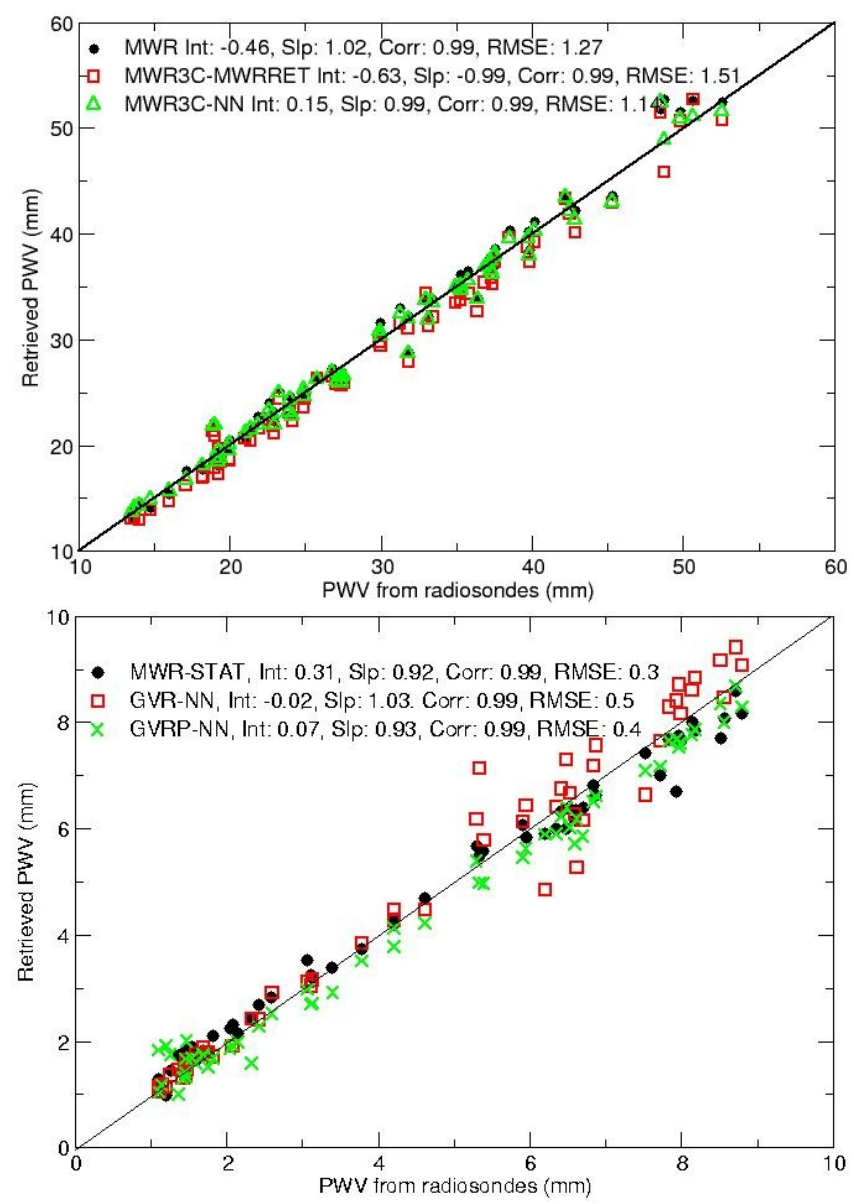

Fig. 11. Top panel: PWV retrieved from the MWR3C and MWR compared to PWV from radiosondes at the SGP site in August 2012 $(N=67)$. Bottom panel: PWV retrieved from the MWR (black dots), GVR (open squares), and GVRP (crosses) compared to PWV from radiosondes at the NSA site in January 2011, $(N=58)$.

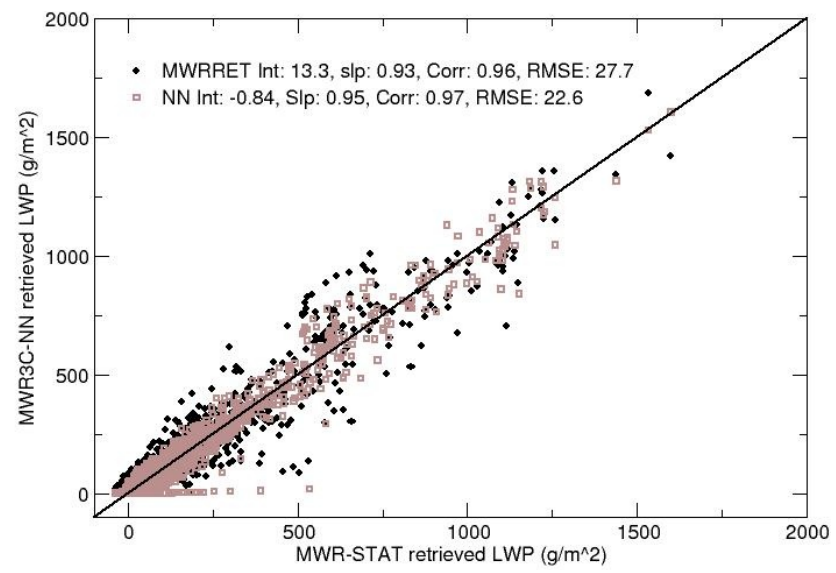

Fig. 12. In the $x$ axis is the LWP retrieved with a linear statistical retrieval from the 2-channel radiometer MWR-STAT. In the $y$ axis is the LWP retrieved from the 3-channel radiometer using a neural network (MWR3C-NN, brown point) and a physical retrieval (MWRRET, black points). Data were collected at the SGP in August 2012, $N=39910$.

MWR-STAT retrievals are derived by applying the derived coefficients to the test ensemble and estimating the RMS error between the computed and the simulated water vapor and liquid water path. These monthly RMS error estimates are provided in the data files. The neural network algorithm computes individual error bars at each observation point. These are estimated by adding a component due to the target noise and a component due to the measurement noise as explained in detail in Cadeddu et al. (2009). In the MWRRET algorithm the retrieval uncertainty is computed from the posterior covariance matrix. Figure 13 shows how the addition of high-frequency channels to the network reduces the retrieval uncertainty. In the left panel, the retrieval uncertainty (expressed as a percentage) is displayed as a function of PWV for the MWR-STAT (green), MWR3C-NN (blue), MWR3C-MWRRET (black), and GVRP-NN (red). Notice that the addition of the $89 \mathrm{GHz}$ channel does not improve the uncertainty in the water vapor retrieval unless a physical retrieval is used, in which case the uncertainty is halved. On the other hand, the addition of frequencies between 170 and $183.3 \mathrm{GHz}$ at the NSA sensibly reduces the PWV uncertainty even with the NN algorithm (red points). In this case, a retrieval uncertainty of $\sim 3-5 \%$ can be achieved when the PWV is less than $10 \mathrm{~mm}$ as noted also by Cimini et al. (2009). In the right panel of Fig. 13, the LWP uncertainty is shown as a function of LWP. The addition of the $89 \mathrm{GHz}$ channel reduces the LWP uncertainty considerably when either the neural network (blue) or the physical retrieval (black) is used, but the uncertainty in the physical retrieval is smaller due to the extra information included in the retrieval process. Higher frequencies $(170-183.3 \mathrm{GHz})$ are useful when the water vapor is low as shown by the red points representing the GVRP$\mathrm{NN}$ at the NSA. 

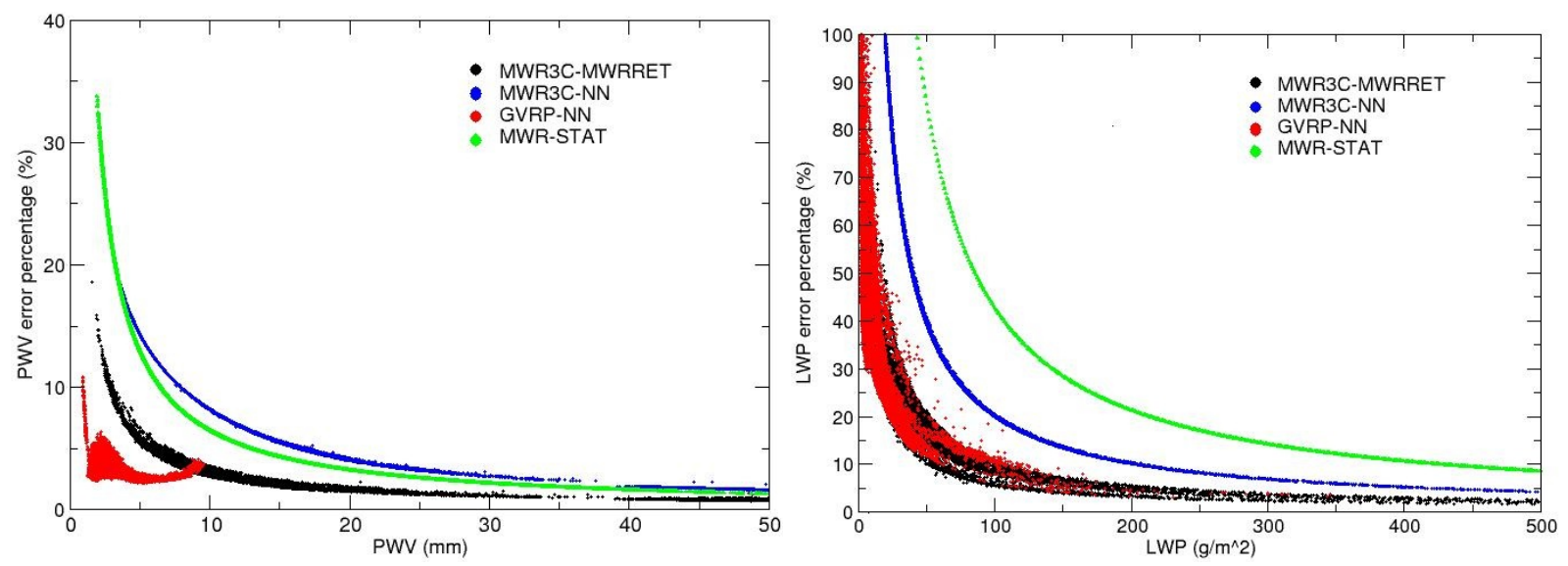

Fig. 13. Errors in the PWV (left panel) and LWP (right panel) retrievals resulting from various combinations of channels and algorithms. MWR3C $(22.834,30,90 \mathrm{GHz})$ with a physical algorithm (MWRRET, black), and a neural network algorithm (NN, blue). MWR (22.8, $31.4 \mathrm{GHz}$ ) with a statistical algorithm (STAT, green), and GVRP (170-183 GHz) with neural network (NN, red).

\section{Vertical profiles of temperature and humidity}

Low-resolution temperature and humidity profiles from the 12-channel microwave radiometers are derived every $5 \mathrm{~min}$ with a seasonal statistical retrieval and are available at two of the ARM sites (see Table 1). The algorithm retrieves profiles of temperature and water vapor density at 47 levels between the surface and a $10 \mathrm{~km}$ altitude. The interpretation of vertical profiles of temperature and humidity from passive sensors requires some caution. Although the retrievals are on 47 levels between 0 and $10 \mathrm{~km}$, the actual vertical resolution of the retrieval is much coarser and depends on the mode of operations (scanning vs. zenith pointing). Because of the exponential decay of the temperature-weighting functions, the highest vertical resolution (approximately $100 \mathrm{~m}$ and $500 \mathrm{~m}$ for temperature and humidity, respectively) is achieved near the surface and in the first $\mathrm{km}$. The vertical resolution of the retrievals degrades rapidly above the first $\mathrm{km}$ in agreement with the conclusions of Cadeddu et al. (2002). Löhnert at al. (2009) showed that the observations have 2-4 degrees of freedom for signal in both temperature and water vapor and the MWRP information is mostly limited to the boundary layer. The degrees of freedom for water vapor profiles vary with the integrated water vapor, being slightly higher in the mid-latitudes and lower in the Arctic. Therefore, the information on the layers above the first $2 \mathrm{~km}$ is derived primarily from the statistical ensemble used to train the retrievals. Monthly temperature and water vapor density retrieval uncertainties are provided at each retrieval level. Additionally profiles of relative humidity, virtual temperature, dew point temperature, and mixing ratio are provided. The profiles have a fairly coarse vertical resolution, however their high temporal resolution can provide useful information on the mesoscale evolution in the boundary layer. In addition MWRP retrievals can be used as a reasonable first-guess for multi-sensor or satellite-based retrievals. Although the accuracy of ground-

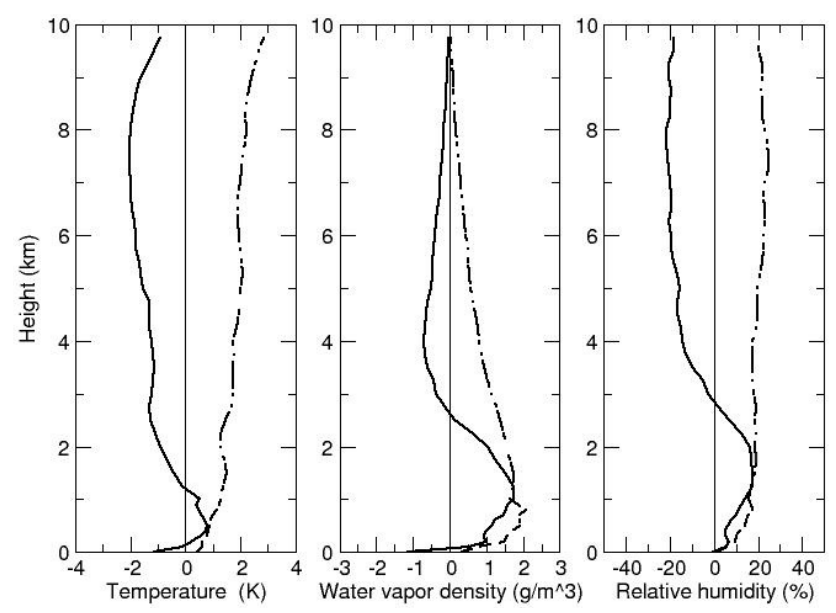

Fig. 14. Mean bias (solid line) and standard deviation (dashed line) of the differences between retrieved (statistical retrieval) and radiosonde-measured profiles of temperature, vapor density and relative humidity $(N=112)$. Data were collected 4 times a day at the AMF1 during October 2012.

based retrievals generally degrades with height, the combination of ground-based and satellite observations can improve the retrieved profile through the entire troposphere (Liljegren et al., 2005; Ebell et al., 2013). The retrievals mean bias and standard deviation for a month of data are shown in Fig. 14. This example illustrates some general features of the radiometric profiles such as a higher accuracy in the first few hundred meters and low vertical resolution in the elevated layers

The ARM-provided retrievals of vertical distribution of cloud liquid water should be used with caution. Figure 2 reveals that the sensitivities of the MWRP frequencies to liquid water are very similar; the sensitivity of the temperaturesensing frequencies to liquid water is also very similar. This means that the MWRP has effectively only two 

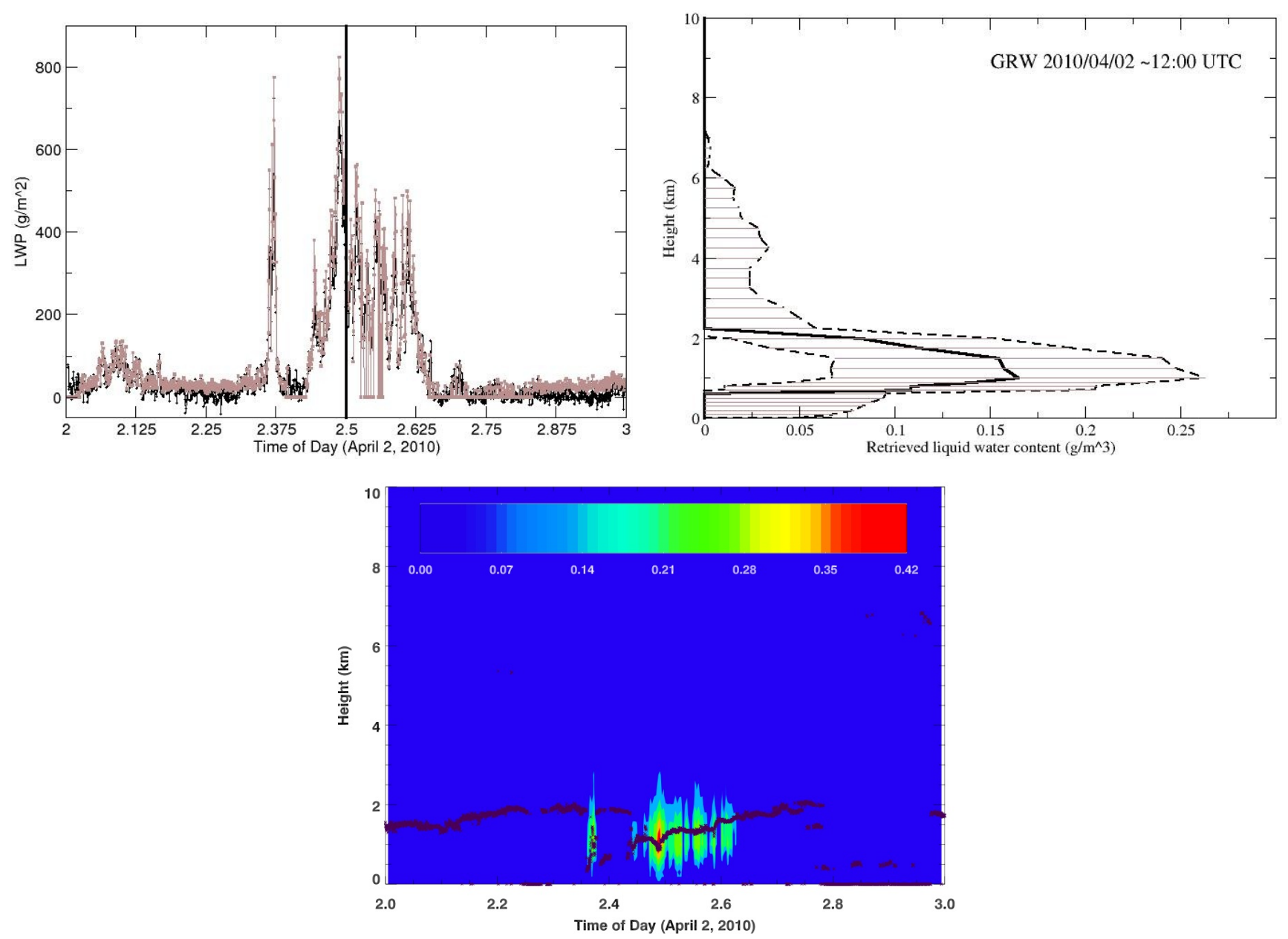

Fig. 15. Top panel: LWP on 2 April 2010 at the AMF1-Azores (black point) and LWP obtained from vertically integrating the LWC retrieval (brown points). The vertical line at 12:00 UTC indicates the time of the displayed LWC retrieval in the right panel. Bottom panel: corresponding profiles of LWC retrieved by the MWRP and cloud base from the ceilometer. Right panel: Vertical profile of LWC retrieved by the MWRP at 12:00 UTC. The black solid line is the retrieval and the area enclosed by dashed lines indicates the retrieval uncertainty.

liquid-sensing frequencies (30 and $51 \mathrm{GHz}$ ). Consequently, the sensitivity to the vertical distribution of liquid water is very low and the retrievals will be dominated by the effect of the prior information used to derive the retrieval coefficients. A discussion of uncertainty in LWC retrieval using only radiometric measurements can be found in Crewell et al. (2009). An example of LWC retrieval is shown in Fig. 15. The top panel shows the integrated liquid water on 2 April 2010 at the AMF1-Azores site. The bottom panel shows the corresponding liquid water content retrieved by the MWRP with a statistical retrieval. It can be noticed that the MWRP retrieves liquid water content (above noise levels) only when the LWP is above $\sim 200 \mathrm{~g} \mathrm{~m}^{-2}$. The left panel shows one single profile collected at 12:00 UTC, when the LWP was approximately $260 \mathrm{~g} \mathrm{~m}^{-2}$. The area enclosed between dashed lines indicates the retrieval uncertainty. From the figure it can be seen that the uncertainty affecting the LWC retrieval in this case can be as high as $100 \%$. Even when thicker clouds are present, retrieval uncertainties vary between $\sim 60 \%$ and $\sim 100 \%$ in agreement with the estimate provided in Crewell et al. (2009). However, it was recently shown that microwave measurements could improve LWC estimates when used in conjunction with cloud radar measurements (Ebell et al., 2010).

\section{Conclusions}

In recent years there has been an interest in the deployment and coordination of networks of ground-based instrumentation (Cimini et al., 2012) and on the complementary use of multiple instruments for the retrieval of 3-dimensional cloud and water vapor fields or validation of satellite retrievals. The long-term use of data from multiple instruments located in different sites and covering different frequency ranges requires high confidence in the long-term calibration and in the retrieval algorithms. 
In this paper, we presented the expanded network of ground-based microwave and millimeter-wave radiometers operated by the US Department of Energy ARM Program Climate Research Facility. We provided an overview of the instruments and their calibration. We showed that the majority of the radiometers are calibrated from the raw data with an automated calibration algorithm specifically developed for the ARM radiometers. The automated algorithm eliminates the need for operator intervention and judgment, ensuring consistent calibrations over time for each instrument as well as among different instruments. The calibration of radiometers that use cryogenic, hot, and warm targets is closely monitored and data are routinely reviewed.

The network was recently expanded to include more frequencies and improved capabilities. With the addition of higher frequencies $(89,90,150,170-197 \mathrm{GHz})$ new algorithms for the retrieval of water vapor and liquid water path have been developed. The new algorithms provide a complement to the already existent retrievals from the 2-channel MWRs. We showed how the addition of higher frequencies reduces the uncertainty associated with the retrievals therefore overcoming some of the limitations that affected the 2-channel MWR retrievals. The new three-channel radiometers (MWR3C) are currently operating at five sites and will eventually replace the 2-channel MWRs at all sites. Although the ARM Program is continually adding new instrumentation and expanding its operations (the addition of two additional sites in under way) the basic principle of operation of the microwave radiometers summarized in this overview are still applicable. All data and retrievals from the ARM radiometers are available for download through the ARM archive at http://www.archive.arm.gov.

Acknowledgements. This work was supported by the US Dept. of Energy under Contract DE-AC02-06CH11357.

D. D. Turner was supported by Atmospheric System Research (ASR) grants DE-SC0006898 and DE-SC0008830.

Data were obtained from the Atmospheric Radiation Measurement (ARM) Program sponsored by the US Department of Energy, Office of Science, Office of Biological and Environmental Research, Environmental Sciences Division.

The submitted manuscript has been created by UChicago Argonne, LLC, Operator of Argonne National Laboratory ("Argonne"). Argonne, a US Department of Energy Office of Science laboratory, is operated under Contract No. DE-AC02-06CH11357. The US Government retains for itself, and others acting on its behalf, a paid-up nonexclusive, irrevocable worldwide license in said article to reproduce, prepare derivative works, distribute copies to the public, and perform publicly and display publicly, by or on behalf of the Government.

Edited by: G. Pappalardo

\section{References}

Braun, J., Rocken, C., and Liljegren, J. C.: Comparisons of lineof-sight water vapor observations using the global positioning system and a pointed microwave radiometer, J. Atmos. Ocean. Technol., 20, 606-612, 2003.

Cadeddu, M. P. and Turner, D. D.: Evaluation of water permittivity models from ground-based observations of cold clouds at frequencies between 23 and $170 \mathrm{GHz}$, IEEE T. Geosci. Remote, 49, 2999-3008, doi:10.1109/TGRS.2011.2121074, 2011.

Cadeddu, M. P., Peckham, G. E., and Gaffard, C.: The vertical resolution of ground-based microwave radiometers analyzed through a multiresolution wavelet technique, IEEE T. Geosci. Remote, 40, 531-540, 2002.

Cadeddu, M. P., Liljegren, J. C., and Pazmany, A.: Measurements and retrievals from a new $183-\mathrm{GHz}$ water vapor radiometer in the Arctic, IEEE T. Geosci. Remote, 45, 2759-2777, 2007.

Cadeddu, M. P., Turner, D. D., and Liljegren, J. C.: A neural network for real-time retrievals of PWV and LWP from arctic millimeter-wave ground-based observations, IEEE T. Geosci. Remote, 47, 1887-1900, 2009.

Cadeddu, M. P.: Microwave Radiometer - High Frequency Handbook, Office of Science, US Department of Energy, DOE/SCARM/TR-080, 2011.

Cady-Pereira, K. E., Shephard, M. W., Turner D. D., Mlawer, E. J., Clough, S. A., and Wagner, T. J.: Improved daytime column-integrated precipitable water vapor from Vaisala radiosonde humidity sensors, J. Atmos. Ocean. Tech., doi:10.1175/2007JTECHA1027.1, 873-883, 2008

Cimini D., Westwater, E. R., Gasiewski, A. J., Klein, M., Leuski, V. Y., and Liljegren, J. C.: Ground-based millimeter- and submillimeter-wave observations of low vapor and liquid water contents, IEEE T. Geosci. Remote, 45, 2169-2180, 2007.

Cimini D., Nasir, F., Westwater, E. R., Payne, V. H., Turner, D. D., Mlawer, E. J., Exner, M. L., and Cadeddu, M. P.: Comparison of ground-based millimeter-wave observations and simulations in the Arctic winter, IEEE T. Geosci. Remote, 47, 3098-3106, 2009.

Cimini, D., Caumont, O., Löhnert, U., Alados-Arboledas, L., Bleisch, R., Fernández-Gálvez, J., Huet, T., Ferrario, M. E., Madonna, F., Maier, O., Nasir, F., Pace, G., and Posada, R.: An International Network of Ground-Based Microwave Radiometers for the Assimilation of Temperature and Humidity Profiles into NWP Models, Proceedings of 9th International Symposium on Tropospheric Profiling, ISBN 978-90-815839-4-7, L'Aquila, Italy 3-7 September 2012.

Clough, S. A., Kneizys, F. X., and Davies, R. W.: Line shape and the water vapor continuum, Atmos. Res., 23, 229-241, 1989.

Crewell, S. and Löhnert, U.: Accuracy of cloud liquid water path from ground-based microwave radiometry. Part II. Sensor accuracy and synergy, Radio Sci., 38, 8042, doi:10.1029/2002RS002634, 2003.

Crewell, S., Ebell, K., Löhnert, U., and Turner, D. D.: Can liquid water profiles be retrieved from passive microwave zenith observations?, Geophys. Res. Lett., 36, L06803, doi:10.1029/2008GL036934, 2009.

Del Genio, A. D. and Wolf, A. B.: The temperature dependence of the liquid water path of low clouds in the Southern Great Plains, J. Climate, 13, 3465-3486, 2000. 
Doran, J. C., Zhong, S., Liljegren, J. C., and Jakob, C.: A comparison of cloud properties at a coastal site and inland site at the North Slope of Alaska, J. Geophys. Res., 107, 4120, doi:10.1029/2001JD000819, 2002.

Ebell, K., Löhnert, U., Crewell, S., and Turner, D. D.: On characterizing the error in a remotely sensed liquid water content profile, Atmos. Res., 98, 57-68, 2010.

Ebell, K., Orlandi, E., Hünerbein, A., Löhnert, U., and Crewell, S.: Combining ground with satellite based measurements in the atmospheric state retrieval: Assessment of the information content, J. Geophys. Res., 118, 13, 6940-6956, 2013.

Greenwald, T. J., Christopher, S. A., Chou, J., and Liljegren, J. C.: Inter-comparison of cloud liquid water path derived from the GOES 9 imager and ground-based microwave radiometers for continental stratocumulus, J. Geophys. Res., 104, 9251-9260, 1999.

Huang, D., Gasiewski, A., Cadeddu, M., and Wiscombe, W.: Cloud Life Cycle Observed During the 2009 Cloud Tomography Field Campaign, poster presentation at the 1st Atmospheric System research meeting, March 15-19, 2010, Bethesda, Maryland

Keihm, S. J., Bar-Sever, Y., and Liljegren, J. C.: WVR-GPS comparison measurements and calibration of the $20-32 \mathrm{GHz}$ tropospheric water vapor absorption model, IEEE T. Geosci. Remote, 40, 1199-1210, 2002.

Liebe, H. J., Hufford, G. A., and Manabe, T.: A model for the complex permittivity of water at the frequencies below $1 \mathrm{THz}$, Int. J. Infrared Millim. Waves, 12, 659-675, 1991.

Liljegren, J. C.: Observations of integrated water vapor and cloud liquid water at the SHEBA ice station: Microwave Radiometry and Remote Sensing of the Earth's Surface and Atmosphere, edited by: Pampaloni, P. and Paloscia, S., Lorton, VA, VSP Book, 155-163, 2000a.

Liljegren, J. C.: Automatic self-calibration of ARM microwave radiometers, Microwave Radiometry and Remote Sensing of the Earth's Surface and Atmosphere, edited by: Pampaloni, P. and Paloscia, S., Lorton, VA, VSP Book, 433-443, 2000 b.

Liljegren, J. C., Clothiaux, E. E., Mace, G. G., Kato, S., and Dong, $\mathrm{X}$.: A new retrieval for cloud liquid water path using a groundbased microwave radiometer and measurements of cloud temperature, J. Geophys. Res., 106, 485-14,500, 2001.

Liljegren, J. C., Boukabara, S.-A., Cady-Pereira, K., and Clough, S. A.: The effect of the half-width of the $22-\mathrm{GHz}$ water vapor line on retrievals of temperature and water vapor profiles with a 12-channel microwave radiometer, IEEE T. Geosci. Remote, 43, 1102-1108, 2005.

Liou, Y. A., Teng, Y. T., Van Hove, T., and Liljegren, J. C.: Comparison of precipitable water observations in the near tropics by GPS, microwave radiometer and radiosondes, J. Appl. Meteorol., 40, 5-15, 2001.

Löhnert, U. and Crewell, S.: Accuracy of cloud liquid water path from ground-based microwave radiometry 1 . Dependency on cloud model statistics: Radio Sci., 38, 8041-8051, doi:10.1029/2002RS002654, 2003.

Löhnert, U., Turner, D. D., and Crewell, S.: Ground-based temperature and humidity profiling using Spectral infrared and microwave observations. Part I: Simulated retrieval performance in clear-sky conditions, J. Appl. Meteor. Clim., 48, 1017-1032, doi:10.1175/2008JAMC2060.1, 2009.
Marchand, R., Ackerman, T., Westwater, E. R., Clough, S. A., Cady-Pereira, K., and Liljegren, J. C.: An assessment of microwave absorption models and retrievals of cloud liquid water using clear-sky data, J. Geophys. Res., 108, 4773, doi:10.1029/2003JD003843, 2003

Mattioli, V., Westwater, E. R., Cimini, D., Liljegren, J. C., Lesht, B. M., Gutman, S. I., and Schmidlin, F. J: Analysis of radiosonde and ground-based remotely sensed PWV data from the 2004 North Slope of Alaska Arctic Winter Radiometric Experiment: J. Atmos. Ocean. Tech., 24, 415-431, doi:10.1175/JTECH1982.1, 2007.

McComiskey, A., Feingold, G., Frisch, A. S., Turner, D. D., Miller, M. A., Chiu, J. S., Min, Q., and Ogren, J. A.: An assessment of aerosol-cloud interactions in marine stratus clouds based on surface remote sensing, J. Geophys. Res., 114, D09203, doi:10.1029/2008JD011006, 2009.

Michalsky, J. J., Liljegren, J. C., and Harrison, L. C.: A comparison of sun photometer derivations of total column water vapor and ozone to standard measures of same at the Southern Great Plains Atmospheric Radiation Measurement site, J. Geophys. Res., 100, 995-26,003, 1995.

Mlawer, E. J., Payne, V. H., Moncet, J.-L., Delamere, J. S., Alvarado, M. J., and Tobin, D. C.: Development and recent evaluation of the MT_CKD model of continuum absorption, Phil. Trans. Roy. Soc. A, 370, 2520-2556, doi:10.1098/rsta.2011.0295, 2011.

Payne, V. H., Delamere, J. S., Cady-Pereira, K. E., Gamache, R. R., Moncet, J.-L., Mlawer, E. J., and Clough, S. A.: Air-broadened half-widths of the 22-GHz and 183-GHz water-vapor lines, IEEE T. Geosci. Remote, 46, 3601-3617, 2008.

Payne, V. H., Mlawer, E. J., Cady-Pereira, K. E., and Moncet, J.-L.: Water Vapor Continuum Absorption in the Microwave, IEEE T. Geosci. Remote, 49, 2194-2208, 2011.

Pazmany, A. L.: A Compact 183-GHz Radiometer for Water Vapor and Liquid Water Sensing, IEEE T. Geosci. Remote, 45, 2202 2206, 2007.

Peppler, R. A., Long, C. N., Sisterson, D. L., Turner, D. D., Bahrmann, C. P., Christensen, S. W., Doty, K. J., Eagan, R. C., Halter, T. D., Ivey, M. D., Keck, N. N., Kehoe, K. E., Liljegren, J. C., Macduff, M. C., Mather, J. H., McCord, R. A., Monroe, J. W., Moore, S. T., Nitschke, K. L., Orr, B. W., Perez, R. C., Perkins, B. D., Richardson, S. J., Sonntag, K. L., Voyles, J. W., and Wagener, R.: An Overview of ARM Program Climate Research Facility Data Quality Assurance, Open Atmos. Sci. J., 2, 192-216, 2008.

Racette, P. E., Westwater, E. R., Han, Y., Gasiewski, A. J., Klein, M., Cimini, D., Jones, D. C., Manning, W., Kim, E. J., Wang, J. R., Leuski, V., and Kiedron, P.: Measurements of Low Amounts of Precipitable Water Vapor Using Ground-Based Millimeterwave Radiometry, J. Atmos. Ocean. Tech., 4, 317-337, 2005.

Revercomb, H. E., Turner, D. D., Tobin, D. C., Knuteson, R. O., Feltz, W. F., Barnard, J., Bosenberg, J., Clough, S., Cook, D., Ferrare, R., Goldsmith, J., Gutman, S., Halthore, R., Lesht, B., Liljegren, J., Linne, H., Michalsky, J., Morris, V., Porch, W., Richardson, S., Schmid, B., Splitt, M., Vanhove, T., Westwater, E., and Whiteman, D.: The Atmospheric Radiation Measurement (ARM) Program's water vapor intensive observation periods: overview, initial accomplishments, and future challenges, B. Am. Meteor. Soc., 84, 217-236, 2003. 
Rose, T., Crewell, S., Löhnert, U., and Simmer, C.: A network suitable microwave radiometer for operational monitoring of the cloudy atmosphere, Atmos. Res., 75, 183-200, 2005.

Schmid, B., Michalsky, J., Slater, D., Barnard, J., Halthore, R., Liljegren, J. C., Holben, B., Eck, T., Slutsker, I., Livingston, J., Russell, P., and Ingold, T.: Comparison of columnar water vapor measurements from solar transmittance methods, J. Appl. Opt., 40, 1886-1896, 2001.

Solheim, F. S.: Use of pointed water vapor radiometer observations to improve vertical GPS surveying accuracy, Ph.D. Thesis, University of Colorado, 128 pp., 1993.

Turner, D. D.: Improved ground-based liquid water path retrievals using a combined infrared and microwave approach, J. Geophys, Res., 112, D15204, doi:10.1029/2007JD008530, 2007.

Turner, D. D. and Goldsmith, J. E. M.: Twenty-four-hour Raman lidar water vapor measurements during the Atmospheric Radiation Measurement Program's 1996 and 1997 water vapor intensive observation periods, J. Atmos. Ocean. Tech., 16, 1062-1076, 1999.

Turner, D. D. and Mlawer, E. J.: The Radiative Heating in Underexplored Bands Campaigns, B. Am. Meteor. Soc., 91, 911-923, 2010.

Turner, D. D., Lesht, B. M., Clough, S. A., Liljegren, J. C., Revercomb, H. E., and Tobin, D. C.: Dry bias and variability in Vaisala radiosondes: the ARM experience, J. Atmos. Ocean. Tech., 20, 117-132, 2003.
Turner, D. D., Vogelmann, A. M., Austin, R. T., Barnard, J. C., Cady-Pereira, K., Chiu, J. C., Clough, S. A., Flynn, C., Khaiyer, M. M., Liljegren, J., Johnson, K., Lin, B., Long, C., Marshak, A., Matrosov, S. Y., McFarlane, S. A., Miller, M., Min, Q., Minnis, P., O'Hirok, W., Wang, Z., and Wiscombe, W.: Thin liquid water clouds: their importance and our challenge, B. Am. Meteorol. Soc., 88, 177-190, 2007a.

Turner, D. D., Clough, S. A., Liljegren, J. C., Clothiaux, E. E., Cady-Pereira, K. E., and Gaustad, K. L.: Retrieving liquid water path and precipitable water vapor from the Atmospheric Radiation Measurement (ARM) microwave radiometers, IEEE T. Geosci. Remote, 45, 3680-3690, 2007b.

Turner, D. D., Cadeddu, M. P., Löhnert, U., Crewell, S., and Vogelmann, A. M.: Modifications to the Water Vapor Continuum in the Microwave Suggested by Ground-Based 150-GHz Observations, IEEE T. Geosci. Remote, 47, 3326-3337, 2009.

Westwater, E. R., Yan, H., Shupe, M. D., and Matrosov, S. Y.: Analysis of integrated cloud liquid and precipitable water vapor retrievals from microwave radiometers during the Surface Heat Budget of the Arctic Ocean project, J. Geophys. Res., 106, 32019-32030, 2001.

Zuidema, P., Leon, D., Pazmany, A., and Cadeddu, M.: Aircraft millimeter-wave passive sensing of cloud liquid water and water vapor during VOCALS-REx, Atmos. Chem. Phys., 12, 355-369, doi:10.5194/acp-12-355-2012, 2012. 